\title{
Characterisation of 20th Century Metallic Paint in Works of Art
}

\author{
R. Wuhrer ${ }^{1}$, P. Dredge ${ }^{2}$, M. Sawicki ${ }^{2}$, L. Allen ${ }^{2}$ and D. Fania ${ }^{3}$ \\ 1. Advanced Materials Characterisation Facility, University of Western Sydney, NSW, Australia \\ 2. Art Gallery of New South Wales, Art Gallery Rd, Sydney, NSW, 2000, Australia \\ 3. School of Science and Health, University of Western Sydney, NSW, Australia
}

A number of art works dating from the late 19th century to the 1960s, in which the artist has used metallic paint, are currently undergoing a detailed technical and analytical study to gather more information about the metallic material, with the overall aim being to assist with the restoration of the art works. The restoration and conservation of paintings requires an understanding of the individual structure of each work of art and often involves the need for 1) correct identification of the pigments as well as the other additives such as metallic flakes and powders used by the artist, 2) a detailed knowledge of the chemical interactions between these pigments as well as the metallic powders and flakes and 3) an understanding of the artist's method of mixing the different materials and the application of these materials to the canvas.

Small paint chips were carefully excised from pre-existing damaged regions in each case study and embedded in polyester resin. These samples were then cross-sectioned with a microtome and examined by optical microscopy and later carbon coated for SEM/EDS and XRM analysis. Each specimen was analysed using a JEOL 840 SEM equipped with a Moran Scientific X-ray microanalysis and mapping system.

Examples of metallic paint were found on paintings by Ralph Balson (1890-1964), Roy de Maistre (1894-1968), Eric Wilson (1911-1946) and Charles Conder (1868-1909). Metallic paint was also found on artist's frames on paintings by Arthur Boyd (1920-1999) and Roland Strasser (18951974). Along with these paintings, two cans of Taubmans metallic paint were examined. These include a tin of Taubmans Silvafros ${ }^{\mathrm{TM}}$ silver coloured paint and Taubmans Solvro ${ }^{\mathrm{TM}}$ gold coloured paint. The date of manufacture for these paint tins is unknown but they are believed to be early twentieth century, possible pre-war.

Examples of what is believed to be copper paint have been found incorporated into the image of An Impressionist (Tom Roberts) c. 1889, by Charles Conder. Abstract (Kitchen Stove) 1943 by Eric Wilson was found to have a silver coloured metallic paint incorporated into the image, which was found to be aluminium (Fig.1). Painting 1941 by Ralph Balson was one of a number of paintings by the artist to exhibit the use of metallic paint of a variety of colours. Optical microscopy under visible light revealed three distinct layers of different metallic powders, taken from an area which appeared as a dark bronze/ gold rectangle and SEM/EDS analysis revealed three different metals, copper, aluminium and brass present. A sample taken from a highly reflective silver rectangle near the centre of the image showed the presence of aluminium in the sample, as well as the presence of bismuth. This could suggest the use of a gilding method that employs burnished bismuth powder for a more reflective finish [1].

Tins of commercially prepared Taubmans Silvafros ${ }^{\mathrm{TM}}$ paint and Taubmans Solvro ${ }^{\mathrm{TM}}$ have provided samples of particular interest due to the binders used in their manufacture. Fourier Transform Infrared Spectroscopy (FTIR) was used to identify the binders in these samples. Tung oil was identified in the Taubmans Solvro ${ }^{\mathrm{TM}}$ and coumarone (1-Benzofuran) was identified in the Taubmans Silvafros ${ }^{\mathrm{TM}}$. These are unusual binders and one in particular; the coumarone may have specific benefits in combination with aluminium metallic powders. 
The variation of the alloy or the purity of the metals used in metal powders controlled the colour and quality of the powder and the resulting paint film [2-3]. The size, shape and leafing ability of the particles in metallic paints all influence the reflectance and protective qualities of metallic paints. Aluminium paints in particular are known for their excellent weather proofing and anticorrosive abilities. A detailed analysis of the composition of metallic films can help provide valuable information and allow a more informed approach to the conservation required.

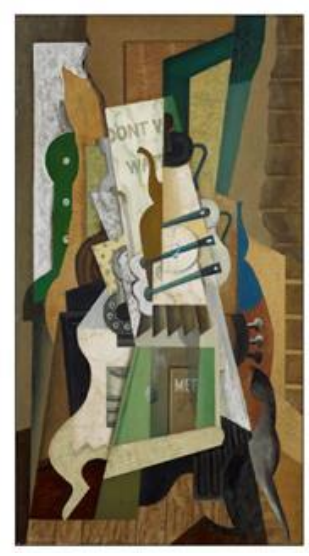

a.


b.



c.

Figure 1: a) Eric Wilson, Abstract (kitchen stove), 1943, alkyd, oil, collage, sand, sawdust, aluminium paint on plywood, 145.5 x 79.7cm. Collection: Art Gallery of New South Wales, Gift of the New South Wales Travelling Art Scholarship Committee 1946, b) Optical images of cross-section and c) BSE image and pseudo colored x-ray map where red is aluminium, green is iron and blue is calcium.

\section{References}

[1]. Gold, Renate. 1998. Reconstruction and Analysis of Bismuth Painting. In: Dorge, Valerie and Howlett, F.Carey, Painted Wood: History and Conservation. Proceedings of a Symposium organised by the Wooden Artifacts Group of the American Institute for Conservation of Historic and Artistic Works and the Foundation of the AIC, held at the Colonial Williamsburg Foundation, Williamsburg, Virginia, 11-14 November 1994, The Getty Conservation Institute, Los Angeles, 166-178 [2]. Hiorns, AH 1892 Metal-colouring and bronzing, Macmillan and Co. London and New York [3]. Thornton J 2000 'All that glitters is not gold: other surfaces that appear to be gilded', in Gilded metals: history, technology and conservation, Drayman-Weisser, T (eds), Archetype Publications in association with the American Institute for Conservation of Historic and Artistic Works, London, pp. 307-317. 